Canadian Journal of Fisheries and Aquatic Sciences Journal canadien des sciences halieutiques et aquatiques

\title{
Evolution of boldness and life-history in response to selective harvesting
}

\begin{tabular}{|c|c|}
\hline Journal: & Canadian Journal of Fisheries and Aquatic Sciences \\
\hline Manuscript ID & cjfas-2016-0350.R2 \\
\hline Manuscript Type: & Article \\
\hline Date Submitted by the Author: & 04-Apr-2017 \\
\hline Complete List of Authors: & $\begin{array}{l}\text { Andersen, Ken; Technical University of Denmark, National Institute of } \\
\text { Aquatic Resources } \\
\text { Marty, Lise; Sorbonne Universités, UPMC Univ Paris 06, INSERM, Institut } \\
\text { Pierre Louis d'Epidémiologie et de Santé Publique (IPLESP UMRS 1136) } \\
\text { Arlinghaus, Robert; Humboldt University of Berlin, }\end{array}$ \\
\hline $\begin{array}{l}\text { Please Select from this Special } \\
\text { Issues list if applicable: }\end{array}$ & N/A \\
\hline Keyword: & $\begin{array}{l}\text { fisheries-induced evolution, timidity syndrome, personality traits, selection } \\
\text { gradients, life-history evolution }\end{array}$ \\
\hline
\end{tabular}

\section{SCHOLARONE \\ Manuscripts}




\section{Evolution of boldness and life-history in response to selective}

\section{2 harvesting}

4 Ken H. Andersen ${ }^{1}$, Lise Marty ${ }^{1,2}$, and Robert Arlinghaus ${ }^{3,4}$

61 Centre for Ocean Life, DTU Aqua, Jægersborg Allé 1, 2920 Charlottenlund, Denmark 2 Institut Pierre Louis d’Epidémiologie et de Santé Publique, UMR_S 1136 INSERM et

8 UPMC, 56 Bd. Vincent Auriol, CS 81393, 75646 Paris cedex 13, France

3 Department of Biology and Ecology of Fishes, Leibniz-Institute of Freshwater Ecology

10 and Inland Fisheries, Müggelseedamm 310, 12587 Berlin, Germany

4 Division of Integrative Fisheries Management, Albrecht-Daniel Thaer Institute of

12 Agricultural and Horticultural Sciences, Faculty of Life Sciences, Philippstrasse 13, Haus

7, 10115 Berlin, Germany

14

Corresponding author: Ken H. Andersen (email: kha@aqua.dtu.dk)

16

18 
20 Abstract

Whether intensive harvesting alters the behavioural repertoire of exploited fishes is

22 currently unknown, but plausible. We extend a fish life-history model to account for boldness as a personality trait that affects foraging intensity, which affects energy

24 intake and risk from predation and fishing gear. We systematically investigate lifehistory and behavioral trait evolution along the boldness-timidity axis in response to

26 the full range of common selectivity and exploitation patterns in fisheries. In agreement with previous studies we find that any type of harvesting selects for fast life histories

28 and that merely elevated, yet unselective, fishing mortality favors boldness. We also find that timid-selective fishing (which can be expected in selected species targeted by

30 active gear types) selects for increased boldness. By contrast, increased timidity is predicted when fishing targets bolder individuals common to passive gears, whether in

32 combination with selection on size or not. Altered behavior caused by intensive harvesting should be commonplace in nature, which can have far-reaching ecological,

34 evolutionary and managerial impacts. Evolution of timidity is expected to strongly erode catchability, which will negatively affect human well-being and influence the

36 reliability of stock assessments that rely on fishery-dependent data.

38 Key words: fisheries-induced evolution, timidity syndrome, personality traits, selection gradients, life-history evolution 


\section{Résumé}

Il est actuellement encore incertain, mais plausible, que la pêche intensive puisse

44 altérer le répertoire de comportements des poissons exploités. Nous étendons un modèle décrivant l'histoire de vie des poissons pour y incorporer un trait de

46 personnalité, l'audace, et examiner de façon systématique l'évolution des traits d'histoire de vie et comportementaux le long de l'axe audace-timidité, en réponse à

48 différents types de sélectivité et d'exploitation couramment rencontrés dans les pêcheries. En accord avec les études précédents, nous montrons que tous les types

50 d'exploitation favorisent une histoire de vie plus rapide et qu'une faible augmentation de mortalité, même non sélective, favorisent une plus grande audace. A l'inverse, une

52 timidité accrue est prédite quand la pêche cible les individus les plus audacieux, cas typique des engins de pêche passifs, que ce soit en combinaison avec la taille ou non.

54 Les modifications du comportement causés par la pêche intensive sont probablement courants dans la nature, ce qui peut avoir d'importantes conséquences écologiques,

56 évolutives et en termes de gestion. En particulier, l'évolution vers une plus grande timidité peut éroder l'attrapabilité, affectant le bien-être des pêcheurs et la fiabilité des

58 évaluations de stock reposant sur des données dépendantes de la pêche. 
Introduction

Assuming that phenotypes expressed by animals in the wild have a heritable basis

62 (Mousseau \& Roff 1987; Dochtermann et al. 2015), harvesting can cause phenotypic and genetic, i.e., evolutionary, changes in exploited populations (Jørgensen et al. 2007;

64 Allendorf \& Hard 2009). For harvesting-induced evolution of life-history traits, such as maturation size or reproductive investment, to occur, it is sufficient that the mortality

66 induced by humans is elevated beyond natural mortality levels because the now altered fitness landscape will select for different phenotypes than natural selection alone

68 would favor (Dieckmann \& Heino 2007; Heino et al. 2015). Evolutionary responses caused by fisheries will be magnified if fishing mortality is not only elevated but

70 selective for fitness-related traits, such as body size (e.g., Edeline et al. 2007; Matsumura et al. 2011; Heino et al. 2015).

Most fishing gear is size-selective, preferentially capturing a certain range of sizes (e.g.,

74 in gill nets) or predominantly harvesting individuals that are larger than a minimum retainment size (e.g., in trawls). A key finding of a range of models and experiments

76 studying the consequences of fisheries-induced selection is that the typical positive-size selection by a trawl that catches both large juvenile and adult individuals induces

78 evolution of fast life histories (Andersen \& Brander 2009; Laugen et al. 2014; Heino et al. 2015). Fast life-histories can be characterized by fast juvenile growth, young age and

80 small size at maturation and high reproductive investment, which reduce postmaturation growth rate and increase natural mortality. From a management 
82 perspective, it is important to understand the population dynamical and social and economic consequences of fisheries-induced evolution, to, if possible, design

84 management tools that minimize undesired evolutionary effects on outcomes valued by humans, such as yield, recovery or the catch prospects of exceptionally large fishes

86 (Matsumura et al. 2011; Eikeset et al. 2013; Zimmermann \& Jørgensen 2017). changes caused by fisheries has focused on life-history traits (Devine et al. 2012; Heino

90 et al. 2015). Our understanding of fisheries-induced selection and potential for evolutionary changes in traits other than life-history traits, such as behavioral or

92 physiological traits, is far less developed (Uusi-Heikkilä et al. 2008; Heino et al. 2015; Arlinghaus et al. 2017). In particular, there is a gap in the knowledge related to the

94 potential for adaptive effects of fishing on behavioral traits in wild-living fish populations. Arlinghaus et al. (2016, in press) recently proposed that wildlife hunting

96 and fishing may foster the evolution of a "timidity syndrome" where adapted populations become shyer, less explorative, less aggressive, less active and/or less bold

98 due to a combination of learning within the realm of plasticity and evolution. Very few on fisheries-induced evolution are available to support these predictions given the lack

100 of behavioural mechanisms present in most theoretical investigations on fisheriesinduced evolution. One exception is a study that included behavioral mechanisms in the 102 analysis of life-history evolution caused by fisheries found that elevated, yet unselective, fishing mortality selected for bolder and/or more aggressive foraging 
104 among juveniles (Jørgensen \& Holt 2013). This finding is the opposite effect of the one proposed by the "timidity syndrome". However, the generality of the results by

106 Jørgensen and Holt (2013) is limited because no size or behavior-selective situations were addressed. In another recent model, Mee et al. (2017) focused on studying the 108 evolution of movement rates in a spatially explicit framework in a sexual fish, but they authors omitted corresponding selection acting on life-history traits. Given the limited

110 scope of previous models, it remains unclear what to expect when fishing not only acts on size, but also on behavioral traits alone or in combination with size, as in most

112 fisheries (Arlinghaus et al. 2017; Diaz Pauli \& Sih 2017).

A rich literature has shown that the behavior expressed by individual fish plays a key role in exposing individuals to fishing gear (Pitcher 1995; Conrad et al. 2011;

116 Løkkeborg et al. 2014). However, the specific behaviors that may be under selection depend on the species and the type of gear. Of relevance is whether the gear is passive,

118 such as gill-nets, traps, commercial long-lines and recreational angling with rod and line, or active, such as trawling or seining. Most passive gear types have been found to select

120 for bold fishes, leaving behind shy individuals (reviewed in Arlinghaus et al. in press, see also Monk and Arlinghaus 2017). For example, an experimental study by Diaz-Pauli et

122 al. (2015) in guppies (Poecilia reticulata) showed that traps selected for shy fishes (by preferentially capturing bold fishes), while experimental trawls selected for bold fishes

124 (by preferentially capturing timid and social fishes). In another experimental study in minnows (Phoxinus phoxinius), Killen et al. (2015) found that experimental trawls 
126 captured fishes with small swimming ability, low basal metabolic rates and low anaerobic scope. Fish with low basal metabolism and often also shy following ideas of

128 the pace-of-life hypothesis (Réale et al. 2010). Based on these findings, one can reasonably assume that passive and active gear types systematically select for opposing

130 behavioural traits. Note, however, that the empirical research based on the relationship of behavioural traits and vulnerability to active gears is much less well developed

132 compared to passive gear types (Diaz-Pauli and Sih in press). Consequently, it is not clear that active gears will always preferentially select shy fishes, but it is safe to

134 assume that fisheries will be generally selective for both size and behavioral traits (Allendorf \& Hard 2009; Heino et al. 2015; Arlinghaus et al. 2017). We therefore

136 explored the whole "sphere of opportunities" in terms of selection acting on the boldness-shyness axis with and without additional selection on size to understand the

138 direction and strength of selection on behaviour and life-history traits in a range of contexts.

For fisheries-induced selection to operate on behavior, it is paramount that

142 behavioral traits are stable phenotypes that characterize individuals within populations. A plethora of recent studies has revealed that fishes indeed reveal less plasticity in their

144 behaviors than previously believed, forming stable among-individual differences in behavioral types (Conrad et al. 2011; Mittelbach et al. 2014). One of the key personality 146 traits in animals in general is boldness (Réale et al. 2007), which is often correlated with other personality traits such as aggression, exploration, sociability or activity, thereby 
148 creating behavioral syndromes (Sih et al. 2004). Behavioral traits are in turn often correlated with physiological and life-history traits, resulting in an integrated phenotype

150 (pace-of-life hypothesis, Réale et al. 2010). For example, boldness (i.e., risk-taking during foraging) has been shown to be correlated with traits associated with a fast-life

152 history (Wolf et al. 2007; Biro \& Stamps 2008; Réale et al. 2010). Hence, life-history traits such as growth rate may change due to direct selection operating on size or due

154 to indirect selection responses caused by direct selection on correlated behavioral traits (Biro \& Post 2008; Biro \& Sampson 2015).

The question addressed here is what selection differentials and life-history

158 responses to expect when a fishery is either unselective, size-selective of various degree or size- and boldness-selective. The baseline prediction is that an entirely unselective

160 fishery with respect to traits and states should lead to the evolution of a fast-life history, which is associated with intensified foraging behavior (i.e., elevated boldness;

162 Jørgensen \& Holt 2013). The reason is simply that intensified foraging allows the individual to gain sufficient resources to achieve fast growth rate as juvenile to invest

164 early into reproduction and devote a large fraction of surplus energy into gonads (Jørgensen and Holt 2013). Such effects should be magnified in a trawl-like fishery that

166 targets large, but possibly shy fishes (Diaz Pauli et al. 2015), if the behavioural selection directly operates on shyness and not on other behavioural traits (e.g., schooling or 168 swimming ability). By contrast, in most passively operated fishing gears (e.g., traps or angling) where the capture probability is usually both size (Kuparinen et al. 2009) and 
170 boldness-related (Klefoth et al. 2012), evolution of a fast-life history with a timid behavioral phenotype should be expected (Arlinghaus et al. 2016, in press). To examine

172 these predictions, we use a quantitative genetics calculation based on a size-based model of fish life history (Andersen and Brander 2009). We included a similar

174 behavioral mechanism to the one used by Jørgensen and Holt (2013) and present the first complete analysis of what selection responses to expect on fish behavioral traits

176 across a range of selectivities, representing a variety of gear types and possible management tools directed at modifying which sizes of fishes can be retained (e.g.,

178 variants of size-based harvest limits).

\section{Material \& methods}

180 The model estimates the evolutionary responses of three fundamental adaptive and heritable traits: boldness $\tau$, size at maturation $w_{\mathrm{m}}$, and size-specific reproductive

182 investment $k_{\mathrm{r}}$. The (fixed) population average of trait $x$ is denoted by a bar: $\bar{x}$. The selection differential $S(\bar{x})$ and the rate of evolutionary change in the average trait,

$184 \mathrm{~d} \bar{x} / \mathrm{d} t$, are calculated using quantitative genetics as in Andersen and Brander (2009). Changes in the three fundamental traits affect growth rate and asymptotic (maximum)

186 body size. The description of the model is divided into three parts: the life-history model, the quantitative genetics calculations, and the determination of the fixed trait 188 values of the unexploited population. 
190 Life-history model

The life-history model presented here is based on earlier work by some of us (Andersen

192 \& Brander 2009). It constitutes a complete description of individual growth, reproduction and survival. The model resolves the vital processes in an average

194 individual as a function of its body size (represented by weight) $w$, and accounts for the trade-off between growth and reproduction (Roff 1983; Lester et al. 2004). Rates of

196 maximum consumption, standard metabolism and natural mortality are assumed to scale with body weight following standard metabolic scaling rules (Brown et al. 2004).

198 Consequently, maximum consumption and standard metabolism is proportional to $w^{n}$, where $n$ is the metabolic exponent, and mortality is proportional to $w^{n-1}$. This way of

200 linking the size-scaling of metabolism and mortality has support from size-spectrum theory, where the exponent $1-n$ on mortality is a result of predation by predators

202 whose need for food scale with exponent $n$ (Sheldon et al. 1977; Andersen \& Beyer 2006). We use the canonical value of the metabolic exponent $n=3 / 4$ but examine the

204 sensitivity of the results to this assumption. The values of the scaling exponents also have empirical support: metabolism and maximum consumption scales with $3 / 4$ for fish

206 (Kiørboe \& Hirst 2014), and mortality with exponent -1/4 (Peterson \& Wroblewski 1984; Lorenzen 2000). We introduce the fundamental trade-off between consumption

208 (leading to growth) and natural mortality (Stamps 2007) into our established model framework to explicitly consider behavioral dynamics and the fishing mortality due to 210 increased risk of predation or exposure to gear while foraging. 
212 Our description of the trade-off related to behaviour is inspired by the classic literature on optimal foraging (Lima \& Bednekoff 1999; Werner \& Anholt 2014). Behaviour is

214 represented by a parameter $\tau \in[0: 1]$, which conceptually is the fraction of time the individual spends foraging. While foraging in risky foraging arenas outside refuges

216 (Ahrens et al. 2012), the individual encounters food, but exposes itself to predation as it typically observed (Lima \& Dill 1990; Biro et al. 2005) and described by optimal foraging

218 theory (McNamara et al. 2001). Given this trade-off, the behavioral process in our model is best described by boldness as personality trait, which is defined in modern

220 behavioural ecology as risk-taking during foraging (Réale et al. 2007). The trade-off implies that bold individuals (those with high $\tau$ ) will have higher consumption and faster

222 growth at the expense of higher predation mortality than timid individuals (low $\tau$ ), for which there is abundant empirical support (Biro et al. 2005; Biro \& Post 2008;

224 Nakayama et al. 2017).

226 The trade-off between growth and mortality is assumed linear: an increasing foraging activity implies a similar increase in predation risk. In reality the trade-off might be non-

228 linear, i.e. with relatively higher or lower mortality risk associated with increased foraging activity. Here, we are only interested in selection responses and therefore only

230 the fitness gradient matters. The trade-off can therefore equally well be viewed as a linearization of the trade-off around the current fixed trait value. It will therefore 232 matter little whether the trade-off is linear or non-linear. 
234 In the following we show how the three fundamental traits, boldness $\tau$, size at maturation $w_{\mathrm{m}}$, and size-specific reproductive investment $k_{\mathrm{r}}$, affect available energy, 236 growth, reproduction, and ultimately mortality.

\section{Available energy}

A foraging individual encounters food with a rate $\tau R_{r}$ where $R_{r}$ is the encountered food

240 (unit biomass per time). The assimilated energy can be described with a Holling functional response type II as

$$
E_{\mathrm{a}}=\epsilon_{\mathrm{a}} C_{\mathrm{m}} \frac{\tau R_{r}}{\tau R_{r}+C_{\mathrm{m}}},
$$

244 where $C_{\mathrm{m}}$ is the maximum consumption rate and $\epsilon_{\mathrm{a}}$ the assimilation efficiency. The maximum consumption rates scales with body weight $w$ as $C_{\mathrm{m}}=A_{\mathrm{m}} w^{n}$, where $A_{m}$ is a

246 constant, $n$ the metabolic exponent, and $w$ the body weight. By defining $A=\epsilon_{\mathrm{a}} A_{\mathrm{m}}$ and $R=R_{r} / C_{\mathrm{m}}$, the assimilated energy can be rewritten in a simpler form as:

$$
E_{\mathrm{a}}=A w^{n} \frac{\tau R}{\tau R+1}
$$

250 Here $R$ is the ratio between encountered food and what can be maximally be consumed. If $R>1$ there is more food available than can be consumed and vice versa.

252 A value of $R \approx 1$ for a fully foraging individual ( $\tau=1$ ) corresponds to a predator 
assimilating at half its assimilative capacity. Assimilation at less than half capacity is

254 usually observed under field conditions (Armstrong \& Schindler 2011), and we therefore assume $R=1$, which with $\tau<1$ leads to assimilation at less than half 256 capacity.

Growth and reproduction

The consumed energy is used for standard metabolism $k_{0} w^{n}$ and activity $k_{a} \tau w$, where

260 the $k^{\prime}$ s are constants and the cost of activity is proportional to the boldness trait $\tau$. Standard metabolism is assumed to scale with the same exponent as the maximum

262 consumption ( $n=3 / 4$ ) while activity is proportional to weight, in accordance with calculations of optimal foraging (Ware 1978). The available energy (assimilated energy

264 minus costs) then becomes

$$
E=A w^{n} \frac{\tau R}{\tau R+1}-k_{0} w^{n}-\tau k_{\mathrm{a}} w
$$

To simplify notation, we define the critical feeding level $f_{\mathrm{c}}=k_{0} w^{n} /\left(A_{\mathrm{m}} w^{n}\right)$ as the 268 ratio between standard metabolism and maximum consumption. This makes it possible to write available energy as

$$
E=A\left(\frac{\tau R}{\tau R+1}-f_{\mathrm{c}}\right) w^{n}-\tau k_{\mathrm{a}} w
$$


272 Reproductive investment is proportional to body mass as is typical for fish (Roff 1983), with a proportionality factor $k_{\mathrm{r}}$. Maturation is described with a function that switches

274 between 0 and 1 around the size at maturation, $w_{m}$ :

$$
\psi\left(w, w_{\mathrm{m}}\right)=\left(1+\left(\frac{w}{w_{\mathrm{m}}}\right)^{-10}\right)^{-1}
$$

276

Growth can then be determined as the remaining available energy after reproduction in 278 adults:

$$
g(w)=A\left(\frac{\tau R}{\tau R+1}-f_{\mathrm{c}}\right) w^{n}-\left(\tau k_{\mathrm{a}}-\psi\left(w, w_{\mathrm{m}}\right) k_{\mathrm{r}}\right) w
$$

As in Andersen and Beyer (2015), we assume that energy is divided between reproduction $k_{\mathrm{r}}$ and activity $k_{\mathrm{a}}$ with a constant fraction $\epsilon_{\mathrm{a}}$. This means that $k_{\mathrm{a}}=$ $k_{\mathrm{r}} \epsilon_{\mathrm{a}} /\left(1-\epsilon_{\mathrm{a}}\right)$. The asymptotic (maximum) size $W$ is reached when somatic growth is 284 zero, i.e., $g(W)=0$ :

$$
W=\left[A\left(\frac{\tau R}{\tau R+1}-f_{\mathrm{c}}\right) \frac{1}{\tau k_{\mathrm{a}}+k_{\mathrm{r}}}\right]^{\frac{1}{1-n}}
$$

which shows that asymptotic size will decrease if investments in reproduction $k_{\mathrm{r}}$ are 288 increased and typically increase if boldness increases (Figure 1). 
290 Mortality

Survival from one size $w_{a}$ to another size $w_{b}$ is found as the solution to $\mathrm{d} P / \mathrm{d} t=$ $292-\mu(w)$ which is:

$$
P_{w_{a} \rightarrow w_{b}}=\exp \left[-\int_{w_{a}}^{w_{b}} \frac{\mu(w)}{g(w)} \mathrm{d} w\right]
$$

296 where $\mu(w)$ is the mortality with contributions from predation and fishing.

298 Predation mortality $\mu_{\mathrm{p}}$ declines with size $\propto w^{n-1}$ as is typical for fish (Peterson \& Wroblewski 1984; Lorenzen 2000) and is assumed proportional to boldness $\tau$ :

$$
\mu_{\mathrm{p}}=\alpha_{p} \tau w^{n-1}
$$

302 Therefore, increased foraging activity by individuals with higher boldness $\tau$ leads to increased predation mortality (as in Jørgensen and Holt 2013). The parameter $\alpha_{p}$ 304 describes the overall level of predation mortality.

306 Fishing is assumed to be unselective or selecting solely on size, solely on boldness or jointly on size and boldness/shyness. The size-selective term is described by a sigmoidal 308 curve (typical for trawling and long-lining, Myers \& Hoenig 1997), switching from zero to one around a size $w_{F}$. Variation in mesh sizes or changes in allowable landing size 
310 (e.g., minimum or maximum-length limit or the combination, a harvest slot) alters sizeselectivity (Jørgensen et al. 2009; Matsumura et al. 2011; Mollet et al. 2016) and is

312 simulated by changing $w_{\mathrm{F}}$ (Figure $2 \mathrm{a}$ ). To simulate a harvest slot fishery (not to be confused with a protected slot-fishery) where only a certain intermediate size-range is

314 targeted (as is common in gill-nets) the selectivity may again go down to zero at a size $w_{\mathrm{FF}}$ (here taken to be 10 times larger than the size where fishing starts) (Figure $2 \mathrm{~b}$ ). The

316 selection on behavior is assumed proportional to boldness, switching around the fixed trait value $\hat{\tau}$ with a steepness $b_{\mathrm{F}}$ (Figure $2 \mathrm{c}$ ). Taken together the fishing mortality $\mu_{F}$

318 then becomes:

$$
\mu_{\mathrm{F}}(w, \tau)=F_{0} \psi\left(w, w_{\mathrm{F}}\right)\left(1-\psi\left(w, w_{\mathrm{FF}}\right)\right)\left(1+b_{\mathrm{F}}(\tau-\bar{\tau})\right)
$$

where $F_{0}$ is the overall fishing mortality, and the dimensionless parameter $b_{\mathrm{F}}$ describes

322 the selection on boldness. Since we only need to evaluate derivatives of $\mu_{F}$ with respect to $\tau$ around $\bar{\tau}$ we will not obtain negative values of $\mu_{F}$. The function $\psi$ is the same that

324 is used to describe maturation around the size at maturation $w_{m}$. Here it describes how selection changes from zero to full selection at the size $w_{F}$ and back again to zero at the 326 size $w_{F F}$. Assuming that selection on boldness by fishing is the same as the boldnessinduced predation mortality corresponds to a value of $b_{\mathrm{F}}=1$. However, we also

328 explore other scenarios of boldness selection, including negative selection where bolder individuals are better at escaping fishing gear as per the research by Diaz-Pauli 330 et al. (2015). The four cases examined further are: 1) random harvest; only elevated 
fishing mortality; 2 ) only size-selective harvest ( $w_{\mathrm{F}}$ and $w_{\mathrm{FF}}$ varied; $\left.b_{\mathrm{F}}=0\right) ; 3$ ) only

332 boldness-selective harvest $\left(w_{\mathrm{F}}=0, w_{\mathrm{FF}}=\infty, b_{F}\right.$ varied around 1); and 4) both sizeand boldness-selective harvest (all parameters are non-zero). A base-case for the size-

334 selectivity is trawl-like fishing in commercial fisheries, which is conceptually similar to exploitation with a minimum-length limit typical in recreational fisheries (positive size-

336 selection) with $F_{0}=0.3 \mathrm{yr}^{-1}, w_{\mathrm{F}}=0.05 \mathrm{~W}$ and $w_{\mathrm{FF}}=\infty$ (Figure 2a).

\section{Quantitative genetics}

Responses to selection depend on the selection differential $S$, which is the mean

340 change in the trait before and after selection (Matsumura et al. 2012). The selection differential is also proportional to the gradient of the life-time reproductive output

342 evaluated around the mean of the fixed trait $\bar{x}$ (Andersen et al. 2007):

$$
S(\bar{x})=\left.\sigma_{x}^{2} \frac{1}{R_{0}(x)} \frac{\partial R_{0}(x)}{\partial x}\right|_{x=\bar{x}}
$$

where $\sigma_{x}$ is the standard deviation of the variation of the trait in the population and the

346 life-time reproductive output is found by integrating individual output multiplied by the survival from egg weight $w_{e g g} \approx 1 \mathrm{mg}$ to asymptotic size:

$$
R_{0} \propto k_{\mathrm{r}} \int_{w_{e g g}}^{W} P_{w_{e g} \rightarrow w} \psi(w, W) w \mathrm{~d} w
$$


350 The constant of proportionality is immaterial because it vanishes when the ratio between the derivative and the value of $R_{0}$ is formed during the calculation of the

352 selection differential.

354 In a natural population unaffected by fishing the selection differential is expected to be zero. However, with given the chosen parameters that was not the case for the traits

356 size at maturation and reproductive investment, meaning that these traits were not in an evolutionarily stable state prior to the commencement of fishing. To address this, we

358 calculate the relative selection differential $S_{\text {fish }}$ due to the selective force from fishing as the difference between the selection responses with and without fishing:

$$
S_{\text {fish }}(\bar{x})=S\left(\bar{x}, F_{0} \neq 0\right)-S\left(\bar{x}, F_{0}=0\right)
$$

362 We choose two variants of normalized selection strength to compare selection on the three adaptive traits. We first calculated the mean-standardized selection gradient

364 (which is perhaps the most suited measure of strength of selection to compare across traits different in mean and variance) and second the proportional selection response.

The mean-standardized selection gradient is given as (Matsumura et al. 2012):

$$
\beta_{\mu}(\bar{x})=\frac{1}{\bar{x}}\left(\frac{\bar{x}}{\sigma_{x}}\right)^{2} S_{\mathrm{fish}}
$$


which has dimensions of $1 /$ generation and represents a fitness elasticity. $\sigma_{x} / \bar{x}$ is the

372 coefficient of variation (CV) of the trait. For simplicity, we choose identical CVs for the three traits examined.

The proportional selection response is the rate of change normalized by the trait value 376 itself, while accounting for the heritability of the trait. It follows from the selection differential as:

$$
r(\bar{x})=\frac{h^{2}}{\bar{x}} S_{\text {fish }}
$$

380 where $h^{2}=0.2$ is the (realistically moderate, compare Mousseau \& Roff 1987;

Dickerson et al. 2005; Thériault et al. 2007) heritability of each of the three traits. Note 382 that the heritability of behavioural traits is often much higher than 0.2 (Dickerson et al. 2005; Dochtermann et al. 2015), such that our model predictions underestimate the 384 evolvability of behavioural traits compared to life-history traits. In the final results, we only report the proportional selection response because the two measures are

386 proportional when the heritability is identical on all traits (Matsumura et al. 2012; eq. 7):

$$
r(\bar{x})=h^{2}\left(\frac{\sigma_{x}}{\bar{x}}\right)^{2} \beta_{\mu}
$$


390 and with the parameters used (Table 1 ) the constant of proportionality is 0.008 . To obtain the values in units of per year, the mean-standardized selection gradient and the

392 selection response are divided by the generation time, approximated as the age of maturation.

\section{Parameter values}

396 The mean values of the three fundamental traits, boldness $\tau$, reproductive investment $k_{\mathrm{r}}$ and size at maturation $w_{\mathrm{m}}$, must be defined at the onset. The value of boldness in

398 the absence of fishery $\bar{\tau}$ is assumed to be the one that optimizes $R_{0}$. We calculate this numerically by finding the value of $\tau$ that gives the highest value of $R_{0}$. The value of the

400 mean reproductive investment $k_{\mathrm{r}}$ effectively determines the asymptotic size via eq. (7). We use $k_{\mathrm{r}}$ to conceptually represent different species of fishes, but report results as a

402 function of asymptotic size. Finally, the size at maturation $w_{\mathrm{m}}$ is assumed proportional to asymptotic size; $w_{\mathrm{m}}=\eta_{\mathrm{m}} W$. This does not imply that $w_{\mathrm{m}}$ and $k_{\mathrm{r}}$ are directly

404 correlated through the calculation of $W$ with eq. (7); this relation is only used to calculate the starting value in the absence of fishing and not in the process of

406 calculating selection responses. The values of the other parameters of the model are given in Table 1.

The model is solved numerically by discretizing the weight-axis in 1000 logarithmically 410 spaced size bins, as described in Andersen \& Beyer (2015, app. C). 


\section{Results}

412 The predicted evolution in the four cases of selectivity patterns (1: random harvest; 2 : only size-selective harvest; 3: only boldness-selective harvest; 4: both size- and

414 boldness-selective harvest) on the three fundamental traits examined here (Figure 3).

416 The first two cases - random harvest and size-selectivity with a trawl-like selectivity pattern - confirms that harvesting leads to the evolution of a fast-life history

418 characterized by reduced size at maturation and increased investment in reproduction. Clearly, the effects of added mortality late in life, where the mortality is large compared

420 to natural mortality, dominates over the effect of added mortality early in life where the mortality is much smaller than the natural mortality (Figure 2). Regarding boldness,

422 both cases leads to evolution of bolder individuals, and the rate of evolution on the boldness trait is much faster than the selection on the life-history traits. Evolution of

424 increased boldness therefore occurs even if fishing gear selects neutrally with respect to boldness. The optimum for the boldness trait before selection is the result of a

426 balance between the benefit of the faster growth that results from higher boldness and the costs of increased predation risk. When mortality is elevated regardless of the

428 boldness, this balance shifts in the direction where the cost of predation mortality becomes less compared to the total mortality. This generates a selection response

430 towards increased boldness. The effect is further compounded by the increased investment in reproduction that comes at the cost of reduced adult growth, which can

432 be compensated by the higher consumption of bolder individuals. Finally, increased 
mortality increases the pressure to ensure survival to maturation to ensure at least one

434 spawning event. This is facilitated by faster juvenile growth.

436 Fishing gear selecting on boldness traits, either solely (case 3) or in conjunction with size-selectivity (case 4), has the same selection responses on size at maturation and

438 reproductive investment as without selection for boldness, i.e., fast life-histories are favored. The main outcome of selection on boldness is an additional selection response

440 towards more timid individuals, leading to a weakening of the selection on boldness. If the selection on boldness is increased $\left(b_{F}>1\right)$ then then the selection response on the

442 personality trait is completely reversed, and instead of selecting for bolder individuals, there is now selection for more timid individuals (Figure 4b). The reason is simply that

444 now there is an increasing cost to be bold by elevating the chances of being captured, which reverses and sharply reduces the evolution of fish boldness in our model. While

446 this outcome is fairly intuitive, it is less obvious, yet in line with expectations, why the absence of selection on boldness leads to increased boldness (case 1 and 2).

The selection responses are roughly proportional to the fishing mortality and, for

450 boldness, to the selection strength acting on boldness (Figure 4). The order of magnitude of the selection responses of the three traits are roughly $0.1 \%$ per year. The

452 selection responses of timidity only exceed the selection responses of the two other traits when selection on boldness is exceedingly large (parameter $b_{\mathrm{F}}$ ) (Figure $4 \mathrm{~b}$ ). By 
454 contrast, when timid fish are more likely to be captured (negative values of $b_{F}$ in Figure 4b), evolution of boldness occurs also under size- and timidity-selective fisheries.

Changes in growth and asymptotic size

458 The combined effects of the selection responses of the three adaptive traits (maturation size, investment in reproduction and boldness) are summarized in the 460 impact of fishing on size-at-age and asymptotic size (Figure 5). In the cases without selection on boldness, the effects of evolution of boldness (leading to faster growth)

462 and increased investment in reproduction (leading to slower growth) cancel one another, and growth is largely unchanged. This result was anticipated by Eq. (7). Clearly,

464 boldness-selectivity in addition to mere size-selectivity has the potential for a magnified change in growth rate leading to a reduction in asymptotic size, in particular for small-

466 bodied fish species.

468 While the result that selecting bolder individuals leads to evolution of more timid individuals (cases 3 and 4) can be understood intuitively, there are two aspects of the

470 results which are less intuitive: $i$ ) why does selection on boldness not affect the direction of the selection responses of life history traits? ii) why does random and trawl

472 selectivity (cases 1 and 2 ) lead to the same selection responses on the life history traits (reproductive investment and size at maturation)? Regarding the first question, the

474 reason lies in the life-time reproductive output being only influenced by the level of mortality imposed, not whether it is selective on boldness or not. The level of mortality, 
476 and thus the level of selection, is only affected when differences in boldness are considered. We can understand the answer to ii) by examining the effects of size

478 selection, as we do next.

480 Sensitivities in response to altered size-selectivity patterns

The selection responses depend on the size-selectivity imposed by the fishery as

482 described by size of $50 \%$ selection relative to asymptotic size $\eta_{F}$ (Figure 6). Most importantly, a shift is seen in when selection changes from targeting both juveniles and

484 adults to when only adult are targeted $\left(\eta_{F} W>\right.$ size at maturation) (Figure 6a). When only adults are targeted the strength of selection declines and the sign of the selection

486 response on boldness changes as the minimum-size limit in the trawl-like selectivity moves up. Selecting only large mature individuals thus is expected to induce timidity,

488 while selecting smaller fishes (including juveniles) selects for boldness when the fishery is entirely size-selective. The reason for this change is that as mortality is decreased on

490 adults it becomes less important to grow fast, and the push towards increased boldness diminishes. When juveniles are also selected $\left(\eta_{F} \ll\right.$ size at maturation), the selection

492 responses on the life history traits become independent on the size at selection. This is likely because for these small sizes natural mortality, which declines with body size, is

494 higher than the fishing mortality, and the effect of the elevated fishing has less selective power. This is the reason why random selection and size-specific selection have similar 496 effects. As before, selection for boldness when the size-selectivity targets also juveniles or small adults is entirely reversed (i.e., timid fish are favoured) when there is also 
498 boldness-selectivity common to many passive fishing gears (Figure 6b). The selection on life-history traits with elevation of minimum-length limits works as before, i.e., direct

500 selection on boldness does not alter the life-history responses of a fast life-history, but the evolutionary response is reduced if only very large adults are targeted.

Gill-net selectivity (which resembles management in recreational fisheries using a

504 harvest slot) leads to more complex selection responses, but does not avoid selection on the three traits (Figure $6 \mathrm{c}+\mathrm{d}$ ). The results are similar to the trawl selectivity pattern

506 when the gill-net only harvests mature individuals. In that case, there is no selection on boldness, and only reproductive investment is predicted to rise (Figure 6c). However,

508 compared to the trawl-like fishery (Figure 6a) the life-history responses and the evolution of boldness are overall reduced (particularly in relation to boldness evolution)

510 when fishing using a harvest slot only selects juvenile individuals (Figure 6c). The lowered selection responses on all three traits is particularly visible when selection

512 operates on both size and boldness (Figure $6 \mathrm{~d}$ ). Then, although under a gill net selectivity, evolution of timidity is predicted when the slot targets mature fishes.

514 Selection responses with gill net selectivity are overall lower compared to a trawl-like selectivity because the cumulative mortality, i.e. the mortality summed over the whole

516 size range, is smaller at a given fishing mortality rate when only a limited size range is selected compared to the range selected by a trawl. 
520 The model relies on the nine parameters in Table $1\left(k_{r}\right.$ is a free parameter that determines the asymptotic size). Selection responses are directly proportional to the

522 heritability $h^{2}$ and to the C.V. of the traits $\sigma_{x} / \bar{x}$. This follows directly from Eqs. (11) and (15). These parameters therefore only affect the absolute magnitude of the selection

524 responses prediction and do not affect the qualitative results of the different selection scenarios. The sensitivity of the selection responses to the other 7 parameters are

526 explored in Figure 7. The selection responses on the three traits are remarkable insensitive to changes in most parameters. Even changing the metabolic exponent $n$

528 has a small effect. While the traits themselves are relatively insensitive to changes in the parameter values, the asymptotic size is more sensitive. We therefore conclude

530 that the predictions on changes in the traits, including boldness, are relatively robust to parameter choices, while the predictions on changes in asymptotic size are less robust

532 and might vary more between species than predicted by the model.

\section{Discussion}

534 The model replicates earlier model studies showing that increased mortality by fishing selects for individuals with a fast life history with earlier maturation and higher

536 reproductive investment. This result emerges regardless of whether selection was size selective or boldness selective. Increased mortality by fishing favours early-maturing

538 individuals at small size, which have a chance to reproduce before being caught. Similarly, individuals that invest more in reproductive output early in life are better off

540 because the likelihood of a future spawning event is greatly diminished when mortality 
rate increases due to fishing. These results are well-known from life-history theory

542 (Stearns 1992), evolutionary fisheries models of various structure (Arlinghaus et al. 2009; Poos et al. 2011; Dunlop et al. 2015a), laboratory experiments with model fish

544 species (Uusi-Heikkilä et al. 2015) and from time-series analysis of phenotypic field data of harvested natural populations (Jørgensen et al. 2007; Devine et al. 2012; Heino et al.

546 2015). We demonstrate that selection on boldness can have strong additional impacts on growth rate and asymptotic size. Selection on boldness has the potential to either

548 enhance or mitigate the selection on growth rate depending on whether fisheries selection is mainly directed at boldness (enhanced response) or whether it acts on top

550 of size-selection (mitigated response). Our work thus underscores Biro and Post's (2008) and Biro and Sampson's (2015) reasoning that any observed changes in growth

552 rate may be caused by direct selection on boldness rather than being caused by sizeselection or by life-history adaptation to elevated mortality alone.

As a further new finding we show that we can expect boldness to either increase or 556 decrease depending on the degree of selection acting on behavioral traits. Based on our findings, elevated, but random mortality favors boldness (as in the model of Jørgensen 558 and Holt 2013), whereas direct selection on boldness alone or in addition to sizeselection favors timidity, qualitative corresponding to the hypothesis by Arlinghaus et 560 al. (2016, in press). In passively operated fishing gear, vulnerability to capture is likely strongly and often mainly boldness-driven (Klefoth et al. 2012; Biro \& Sampson 2015), 562 which is why one can expect changes in growth rate and evolution of timidity 
particularly in reaction to exploitation by gill nets, traps or hook-and-line. It will be

564 important to test this clear-cut prediction in the future in empirical settings, because increased timidity will have substantial effects on catchability and hence on stock

566 assessment, fisher well-being and effectiveness of management tools such as protected areas (Januchowski-Hartley et al. 2011; Alós et al. 2016; Arlinghaus et al. 2017).

\section{Evolution of behavior}

570 Selection on boldness has the potential to somewhat mitigate the selection response towards a faster life history by inducing timidity and thus slower juvenile growth rates.

572 It does, however, not change the selection on size at maturation and investment in reproduction. However, if timid fish are selectively captured (as might be the case in

574 some active gear types; Diaz-Pauli et al. 2015; Killen et al. 2015), evolution of boldness is also predicted under size- and boldness selective fisheries. How a given fishery selects

576 on boldness depends on the nature of the fishing operation in relation to speciesspecific behavioral patterns and life-styles, which constitutes a much needed research

578 area for the future (Heino et al. 2015; Arlinghaus et al. in press; Diaz-Pauli and Sih in press). Before that research becomes available, we can tentatively propose that

580 because passive gears, such as a gill nets, traps, or hooks, require individuals to actively enter the gear, these gears should preferentially target bold individuals and hence

582 select for elevated timidity (the "timidity syndrome", Arlinghaus et al. 2016, in press). How active gear, such as trawl or purse seines, targets different behavioral types is less 584 known, but if they preferentially target timid individuals (Diaz-Pauli and Sih in press), 
according to our model they will select for bold individuals, amplifying the selection

586 responses induced by elevated mortality and leading to even faster life histories and strongly elevated natural mortality (Jørgensen and Holt 2013). However, trawls might

588 also select on other personality traits such as swimming activity or sociability or physiological traits such as metabolic scope and ability for sustained swimming (Diaz-

590 Pauli et al. 2015; Killen et al. 2015) - traits not considered in our model. Similarly, there is evidence that other active gear types such as spear guns favor less explorative and

592 timid individuals rather than bold ones (Januchowsky-Hartley et al. 2011), suggesting that not all active gear types preferentially exploit shy fishes. Without a dedicated

594 model that considers a range of behavioural traits and their correlations, it is very hard to come up with precise predictions about which behaviours will exactly change in trawl

596 and other active gear-type fisheries. Future theoretical and empirical research is needed in this underexplored area.

\section{Model limitations}

600 The changes in three fundamental life-history and behavioural traits (size at maturation, investment in reproduction and boldness) were found to lead to changes in

602 adult growth rate and a reduction in asymptotic size, which is a classical prediction about the consequences of fisheries-induced evolution (Jørgensen et al. 2007, Laugen

604 et al. 2014). However, we find that the prediction on changes in asymptotic size is at the same time fairly uncertain, as it relies on the value of the parameter $\epsilon_{A}$ that 606 describes the partitioning of energy between activity and reproduction, which is not 
well known empirically (Andersen \& Beyer 2015). Changes in asymptotic size may also

608 be driven by changes in allocation to reproduction during ontogeny, which is unresolved by the model. Instead, we have assumed that allocation to reproduction is

610 directly proportional to individual size, as is customary in many life-history models, however, if allocation increases faster than proportional with size (Edeline et al. 2007;

612 Quince et al. 2008) more energy will be allocated to reproduction in larger individuals, and the reductions in asymptotic size will be even stronger than we predict.

614 Importantly, however, the downsizing of adults is reduced if behavior is considered under selection in addition to size, which will be the default case in many fisheries (Biro 616 and Post 2008; Uusi-Heikkilä et al. 2008; Arlinghaus et al. in press). Therefore, evolutionary costs while considering behavior with respect to size are smaller from an

618 adult size (and likely yield) perspective than assumed before in life-history models that omit behavioral dynamics. Importantly, a recent experimental harvesting experiment in 620 zebrafish (Danio rerio) that strongly selected on size found evolution of timidity and at the same time only subtle changes in terminal size and no evolution of juvenile growth 622 rate (Uusi-Heikkilä et al. 2015), agreeing with our findings.

624 Another limitation of our modelling approach is the absence of population regulation through density-dependent processes, which is a key ingredient of alternative

626 individual-based eco-genetic models of fisheries-induced evolution (Dunlop et al. 2015b; Eikeset et al. 2016). A previous modelling study that examined the impact of a 628 range of density-dependent processes acting on fecundity and mortality on selection 
differentials on reproductive investment in pike (Esox lucius) (Arlinghaus et al. 2009)

630 indeed found that the predictions were rather sensitive to density-dependent somatic growth but insensitive to density-dependent mortality. However, the sign of the

632 selection differentials on reproductive investment remained identical whether densitydependence was acting on growth or not. Moreover, the key predictions emerging from

634 our stylized model were roughly similar to the predictions of more complex eco-genetic models in terms of the expected evolution of fast life histories under most situations in

636 fisheries (Eikeset et al. 2013; Dunlop et al. 2015b). Nevertheless, it is clear that our work shall be extended and replicated with other model frameworks to analysis its

638 stability. Further, our model assumes that the entire stock is only exposed to one gear type selectivity. Our findings do not hold for mixed gear situations, which demand

640 careful calibration to actually selection pressures caused by varying gear and the modelling of spatial gene flow. The scope of our work is beyond this, but some recent

642 work has started to look at spatial explicit models (Mee et al. 2017). Finally, it is important to consider multi-species contexts in future evolutionary models and a range

644 of behavioural traits that are either correlated with each other forming behavioural syndromes (Sih et al. 2004) or independently affecting vulnerability to capture and

646 resource intake (e.g., boldness and activity or space use). Empirical research is needed to provide the data about correlations among traits to inform such models. Until that

648 research becomes available our predictions on the relative impact of size-selectivity and boldness-selectivity represents the best possible estimates, and they were found to be 650 independent of specific assumptions and size-selectivity of fishing. Our results on the 
magnitudes of evolutionary rates, however, are more uncertain as they depend on

652 exact values of parameters. Least robust are our predictions on changes in asymptotic size. Moreover, our findings on the relative impacts of gill net selectivity confounded

654 effects stemming from altered size-selection with altered effective exploitation rates (not the case in Mollet et al. 2016), warranting further study in the future.

656

\section{Consequences}

658 Based on our current knowledge, we propose that predicting the evolutionary consequences of fisheries for populations will benefit from explicit consideration of

660 behavioral dynamics. In the absence of more detailed knowledge, it is possible that active gear that targets timid individuals (Diaz-Pauli and Sih in press) will select for

662 bolder fishes. This result is valid even in the absence of direct selection on boldness, but will be even stronger if timid fishes are preferentially captured (as might be the case in

664 active gear types Diaz-Pauli et al. 2015). Conversely, passive gear is more robustly known to target bold individuals (which often have faster life histories, Réale et al.

666 2010), thereby evolutionarily favoring increased timidity. Many commercial and recreational fisheries operate with passive gear - long lining for pelagic top predators in

668 the ocean, gill netting in coastal areas or recreational fishing of freshwater lakes. It is conceivable that a century of such fishing has created shyer individuals with lower

670 consumption rates and more risk averse life-styles, which may in turn translate to reduced parental care in species providing this care (Sutter et al. 2012). This likely has 672 consequences for social groups, populations and food webs (Arlinghaus et al. in press; 
Diaz-Pauli and Sih in press), and we also predict systematic erosion of catchability

674 through evolution of timidity (Alós et al. 2015; Philipp et al. 2015; Tsuboi et al. 2016) largely independent of which harvest regulations (minimum-size limits, maximum-size

676 limit or harvest slot) are put in place. This is a major difference to previous studies who found that life-history responses to fishing mortality can well be addressed by cutting

678 fishing mortality and changing selectivity patterns to a dome-shaped selectivity typical of harvest slots and gill nets (e.g., Jørgensen et al. 2009; Matsumura et al. 2011;

680 Zimmermann \& Jørgensen 2017). Our work instead suggests that evolution of timidity by passive gear cannot be avoided unless the harvest slot leads to an exclusive removal

682 of juveniles, which is uncommon in most fisheries but indeed reported from selected recreational fisheries (e.g., in shore recreational fisheries in Florida).

Importantly, because evolution in boldness, in either direction, will erode the index

686 value of fishery-dependent data by changing catchability over time, and have potentially have large community and food web as well as managerial and fisheries

688 consequences (Arlinghaus et al. in press), we (and others, Diaz-Pauli and Sih in press) suggest increasing attention to the possibility of fisheries shaping the mean and 690 variance of behavioral expressed by exploited fishes in nature.

\section{Acknowledgement}

KHA and LM were supported by the Centre for Ocean Life, a VKR Centre of Excellence

694 funded by the Villum Foundation. RA thanks Leander Höhne for editorial assistance. 
696 References

Ahrens RNM, Walters CJ, Christensen V (2012) Foraging arena theory. Fish Fish 13:41698 59

Allendorf FW, Hard JJ (2009) Human-induced evolution caused by unnatural selection through harvest of wild animals. 106:9987-9994

Alós J, Palmer M, Balle S, Arlinghaus R (2016) Bayesian state-space modelling of conventional acoustic tracking provides accurate descriptors of home range behavior in a small-bodied coastal fish species. PLoS One 11:e0154089

704 Alós J, Palmer M, Trías P, Díaz-Gil C, Arlinghaus R (2015) Recreational angling intensity correlates with alteration of vulnerability to fishing in a carnivorous coastal fish species. Can J Fish Aquat Sci 72:217-225

Andersen KH, Beyer JE (2006) Asymptotic size determines species abundance in the marine size spectrum. Am Nat 168:54-61

Andersen KH, Beyer JE (2015) Size structure, not metabolic scaling rules, determines fisheries reference points. Fish Fish 16:1-22

Andersen KH, Brander K (2009) Expected rate of fisheries-induced evolution is slow. Proc Natl Acad Sci USA 106:11657-11660

Andersen KH, Farnsworth KD, Thygesen UH, Beyer JE (2007) The evolutionary pressure 714 from fishing on size at maturation of Baltic cod. Ecol Modell 204:246-252

Arlinghaus R, Alós J, Klefoth T, Laskowski K, Monk CT, Nakayama S, Schröder A (2016)

716 Consumptive tourism causes timidity, rather than boldness, syndromes: A response to Geffroy et al. Trends Ecol Evol 31:92-94 
718 Arlinghaus R, Laskowski K, Alos J, Klefoth T, Monk CT, Nakayama S, Schröder A (2017) Passive gear-induced timidity syndrome in wild fish populations and its potential 720 ecological and managerial implications. Fish Fish 18(2) 360-373.

Arlinghaus R, Matsumura S, Dieckmann U (2009) Quantifying selection differentials

722 caused by recreational fishing: development of modeling framework and application to reproductive investment in pike (Esox lucius). Evol Appl 2:335-355

724 Armstrong JB, Schindler DE (2011) Excess digestive capacity in predators reflects a life of feast and famine. Nature 476:84-87

726 Beverton RJH (1992) Patterns of reproductive strategy parameters in some marine teleost fishes. J Fish Biol 41:137-160

728 Biro PA, Post JR (2008) Rapid depletion of genotypes with fast growth and bold personality traits from harvested fish populations. Proc Natl Acad Sci U S A

$730 \quad 105: 2919-2922$

Biro PA, Post JR, Abrahams M V. (2005) Ontogeny of energy allocation reveals selective pressure promoting risk-taking behaviour in young fish cohorts. Proc R Soc London B Biol Sci 272:1443-1448

734 Biro PA, Sampson P (2015) Fishing directly selects on growth rate via behaviour: implications of growth-selection that is independent of size. Proc R Soc B 282:13$736 \quad 15$

Biro PA, Stamps JA (2008) Are animal personality traits linked to life-history productivity? Trends Ecol Evol 23:361-368

Brown JH, Gillooly JF, Allen AP, Savage VM, West GB (2004) Toward a metabolic theory 
of ecology. Ecology 85:1771-1789

Conrad JL, Weinersmith KL, Brodin T, Saltz JB, Sih A (2011) Behavioural syndromes in

742 fishes: A review with implications for ecology and fisheries management. J Fish Biol 78:395-435

744 Devine JA, Wright PJ, Pardoe HE, Heino M (2012) Comparing rates of contemporary evolution in life-history traits for exploited fish stocks. Can J Fish Aquat Sci 69:1105-1120

Diaz Pauli B, Sih A (2017) Behavioural responses to human-induced change: Why fishing 748 should not be ignored. Evol Appl:in press

Diaz Pauli B, Wiech M, Heino M, Utne-Palm AC (2015) Opposite selection on behavioural types by active and passive fishing gears in a simulated guppy Poecilia reticulata fishery. J Fish Biol 86:1030-1045

752 Dickerson BR, Willson MF, Bentzen P, Quinn TP (2005) Heritability of life history and morphological traits in a wild pink salmon population assessed by DNA parentage $754 \quad$ analysis. Trans Am Fish Soc 134:1323-1328

Dieckmann U, Heino M (2007) Probabilistic maturation reaction norms: Their history, 756 strengths, and limitations. Mar Ecol Prog Ser 335:253-269

Dochtermann NA, Schwab T, Sih A (2015) The contribution of additive genetic variation 758 to personality variation: heritability of personality. Proc R Soc London B Biol Sci 282:20142201

760 Dunlop ES, Eikeset AM, Stenseth NC (2015a) From genes to populations: How fisheriesinduced evolution alters stock productivity. Ecol Appl 25:1860-1868 
762 Dunlop ES, Eikeset AM, Stenseth NC (2015b) From genes to populations: how fisheriesinduced evolution alters stock productivity. Ecol Appl 25:1860-1868

764 Edeline E, Carlson SM, Stige LC, Winfield IJ, Fletcher JM, James J Ben, Haugen TO, Vøllestad LA, Stenseth NC (2007) Trait changes in a harvested population are 766 driven by a dynamic tug-of-war between natural and harvest selection. Proc Natl Acad Sci U S A 104:15799-804

768 Eikeset AM, Dunlop ES, Heino M, Storvik G, Stenseth NC, Dieckmann U (2016) Roles of density-dependent growth and life history evolution in accounting for fisheries-

$770 \quad$ induced trait changes. Proc Natl Acad Sci 113:201525749

Eikeset AM, Richter A, Dunlop ES, Dieckmann U, Stenseth NC (2013) Economic repercussions of fisheries-induced evolution. Proc Natl Acad Sci U S A 110:1225964

774 Hartvig M, Andersen KH, Beyer JE (2011) Food web framework for size-structured populations. J Theor Biol 272:113-122

776 Heino M, Díaz Pauli B, Dieckmann U (2015) Fisheries-Induced Evolution. Annu Rev Ecol Evol Syst 46:461-480

778 Januchowski-Hartley FA, Graham NAJ, Feary DA, Morove T, Cinner JE (2011) Fear of fishers: human predation explains behavioral changes in coral reef fishes. PLoS

$780 \quad$ One 6:e22761

Jørgensen C, Enberg K, Dunlop ES, Arlinghaus R, Boukal DS, Brander K, Ernande B, 782 Gårdmark AG, Johnston F, Matsumura S, Pardoe H, Raab K, Silva A, Vainikka A, Dieckmann U, Heino M, Rijnsdorp AD, Gardmark A, Johnston F, Matsumura S, 
Pardoe H, Raab K, Silva A, Vainikka A, Dieckmann U, Heino M, Rijnsdorp AD (2007)

Managing evolving fish stocks. Science 318:1247-1248

786 Jørgensen C, Ernande B, Fiksen $\varnothing$ (2009) Size-selective fishing gear and life history evolution in the Northeast Arctic cod. Evol Appl 2:356-370

788 Jørgensen C, Holt RE (2013) Natural mortality: Its ecology, how it shapes fish life histories, and why it may be increased by fishing. J Sea Res 75:8-18

790 Killen SS, Nati JJH, Suski CD (2015) Vulnerability of individual fish to capture by trawling is influenced by capacity for anaerobic metabolism. Proc Biol Sci 282:20150603

792 Kiørboe T, Hirst AC (2014) Shifts in mass-scaling of respiration, feeding, and growth rates across life-form transitions in marine pelagic organisms. Am Nat

794 Klefoth T, Skov C, Krause J, Arlinghaus R (2012) The role of ecological context and predation risk-stimuli in revealing the true picture about the genetic basis of

796 boldness evolution in fish. Behav Ecol Sociobiol 66:547-559

Kuparinen A, Kuikka S, Merilaa J (2009) Estimating fisheries-induced selection:

798 Traditional gear selectivity research meets fisheries-induced evolution. Evol Appl $2: 234-243$

800 Laugen AT, Engelhard GH, Whitlock R, Arlinghaus R, Dankel DJ, Dunlop ES, Eikeset AM, Enberg K, Jørgensen C, Matsumura S, Nusslé S, Urbach D, Baulier LC, Boukal DS, 802 Ernande B, Johnston FD, Mollet F, Pardoe H, Therkildsen NO, Uusi-Heikkilä S, Vainikka A, Heino M, Rijnsdorp AD, Dieckmann U (2014) Evolutionary impact 804 assessment: Accounting for evolutionary consequences of fishing in an ecosystem approach to fisheries management. Fish Fish 15:65-96 
806 Lester NP, Shuter BJ, Abrams PA (2004) Interpreting the von Bertalanffy model of somatic growth in fishes: the cost of reproduction. Proc R Soc London B 271:1625$808 \quad 1631$

Lima SL, Bednekoff PA (1999) Temporal variation in danger drives antipredator 810 behavior: The predation risk allocation hypothesis. Am Nat 153:649-659

Lima SL, Dill LM (1990) Behavioral decisions made under the risk of predation: a review and prospectus. Can J Zool 68:619-640

Løkkeborg S, Ivar S, Anne OH, Ferter CUK (2014) Towards more efficient longline

814 fisheries: fish feeding behaviour, bait characteristics and development of alternative baits. Reviews in Fish Biology and Fisheries 24(4) 985-1003

816 Lorenzen K (2000) Allometry of natural mortality as a basis for assessing optimal release size in fish-stocking programmes. Can J Fish Aquat Sci 57:2374-2381

818 Matsumura S, Arlinghaus R, Dieckmann U (2011) Assessing evolutionary consequences of size-selective recreational fishing on multiple life-history traits, with an

820 application to northern pike (Esox lucius). Evol Ecol 25:711-735

Matsumura S, Arlinghaus R, Dieckmann U (2012) Standardizing selection strengths to

822 study selection in the wild: a critical comparison and suggestions for the future. Bioscience 62:1039-1054

824 McNamara JM, Houston Al, Collins EJ (2001) Optimality models in behavioral biology. Siam Rev 43:413-466

826 Mee JA, Otto SP, Pauly D (2017) Evolution of movement rate increases the effectiveness of marine reserves for the conservation of pelagic fishes. Evol 
Appl:doi:10.1111/eva.12460

Mittelbach GG, Ballew NG, Kjelvik MK (2014) Fish behavioral types and their ecological consequences. Can J Fish Aquat Sci 71:927-944

Mollet FM, Poos JJ, Dieckmann U, Rijnsdorp AD (2016) Evolutionary impact assessment of the North Sea plaice fishery. Can J Fish Aquat Sci 73:1126-1137

Monk, C. T., Arlinghaus, R. (2017). Encountering a bait is necessary but insufficient to explain individual variability in vulnerability to angling in two freshwater benthivorous fish in the wild. PLoS ONE 12(3): e0173989

836 Mousseau TA, Roff DA (1987) Natural selection and the heritability of fitness components. Heredity (Edinb) 59:181-197

838 Myers RA, Hoenig JM (1997) Direct estimates of gear selectivity from multiple tagging experiments. Can J Fish Aquat Sci 54:1-9

840 Nakayama S, Rapp T, Arlinghaus R (2017) Fast-slow life history is correlated with individual differences in movements and prey selection in an aquatic predator in the wild. J Anim Ecol:in press

Peterson I, Wroblewski J (1984) Mortality Rate of Fishes in the Pelagic Ecosystem. Can J Fish Aquat Sci 41:1117-1120

Philipp DP, Claussen JE, Koppelman JB, Stein JA, Cooke SJ, Suski CD, WahI DH, Sutter DAH, Arlinghaus R (2015) isheries-induced evolution in largemouth bass: linking vulnerability to angling, parental care, and fitness. Am Fish Soc Symp 82:223-234

848 Pitcher TJ (1995) The impact of pelagic fish behaviour on fisheries. Sci Mar 59:295-306 Poos JJ, Brännström Å, Dieckmann U (2011) Harvest-induced maturation evolution 
850 under different life-history trade-offs and harvesting regimes. J Theor Biol 279:102-112

852 Quince C, Abrams PA, Shuter BJ, Lester NP (2008) Biphasic growth in fish I: theoretical foundations. J Theor Biol 254:197-206

854 Réale D, Garant D, Humphries MM, Bergeron P, Careau V, Montiglio P-O (2010) Personality and the emergence of the pace-of-life syndrome concept at the 856 population level. Philos Trans R Soc B Biol Sci 365:4051-4063

Réale D, Reader SM, Sol D, McDougall PT, Dingemanse NJ (2007) Integrating animal 858 temperament within ecology and evolution. Biol Rev 82:291-318

Roff DA (1983) An allocation model of growth and reproduction in fish. Can J Fish Aquat 860 Sci 40:1395-1404

Sheldon RW, Sutcliffe Jr. WH, Paranjape MA (1977) Structure of pelagic food chain and 862 relationship between plankton and fish production. J Fish Res Board Canada $34: 2344-2353$

864 Sih A, Bell A, Johnson JC (2004) Behavioral syndromes: An ecological and evolutionary overview. Trends Ecol Evol 19:372-378

866 Stamps JA (2007) Growth-mortality tradeoffs and "personality traits" in animals. Ecol Lett 10:355-363

868 Stearns SC (1992) The evolution of life histories. Oxford University Press, Oxford Sutter DAH, Suski CD, Philipp DP, Klefoth T, Wahl DH, Kersten P, Cooke SJ, Arlinghaus R 870 (2012) Recreational fishing selectively captures individuals with the highest fitness potential. Proc Natl Acad Sci U S A 109:20960-20965 
872 Thériault V, Garant D, Bernatchez L, Dodson JJ (2007) Heritability of life-history tactics and genetic correlation with body size in a natural population of brook charr

874 (Salvelinus fontinalis). J Evol Biol 20:2266-2277

Tsuboi J, Morita K, Klefoth T, Endou S, Arlinghaus R, Moran P (2016) Behaviour-

876 mediated alteration of positively size-dependent vulnerability to angling in response to historical fishing pressure in a freshwater salmonid. Can J Fish Aquat 878 Sci 73:461-468

Uusi-Heikkilä S, Whiteley AR, Kuparinen A, Matsumura S, Venturelli PA, Wolter C, Slate 880 J, Primmer CR, Meinelt T, Killen SS, Bierbach D, Polverino G, Ludwig A, Arlinghaus R (2015) The evolutionary legacy of size-selective harvesting extends from genes to populations. Evol Appl 8:597-620

Uusi-Heikkilä S, Wolter C, Klefoth T, Arlinghaus R (2008) A behavioral perspective on 884 fishing-induced evolution. Trends Ecol Evol 23:419-21

Ware DM (1978) Bioenergetics of pelagic fish: theoretical change in swimming speed 886 and ration with body size. J Fish Res Board Canada 35:220-228

Werner EE, Anholt BR (2014) Ecological consequences of the trade-off between growth and mortality mediated by foraging activity. Am Nat 142:242-272

West GB, Brown JH, Enquist BJ (2001) A general model for ontogenetic growth. Nature 890 413:628-631

Wolf M, Doorn GS van, Leimar O, Weissing FJ (2007) Life-history trade-offs favour the 892 evolution of animal personalities. Nature 447:581-4

Zimmermann F, Jørgensen C (2017) Taking animal breeding into the wild: regulation of 
894 fishing gear can make fish stocks evolve higher productivity. Mar Ecol Prog Ser 563:185-195

896 
900 Table 1. Value of parameters

\begin{tabular}{lll} 
Parameter & Value and units & Eq. \\
\hline Reproductive investment & $k_{r}\left(\mathrm{yr}^{-1}\right)$ & \\
Size at maturation & $w_{m}(\mathrm{~g})$ & \\
Boldness & $\tau$ & 4 \\
Critical feeding level (1) & $f_{c}=0.2$ & 2 \\
Available food (2) & $R=1$ \\
Mortality constant (3) & $\alpha_{p}=1.9$ & 9 \\
Metabolic exponent (5) & $n=3 / 4$ & 2 \\
Max. consumption parameter & $A=19 \mathrm{~g}^{1-\mathrm{n} / \mathrm{yr}}$ & 2
\end{tabular}

(4)

$\begin{array}{lll}\text { Activity coefficient (6) } & \epsilon_{a}=0.8 & \\ \text { Maturation rel. to } W(7) & \eta_{m}=0.25 & \\ \text { Heritability } & h^{2}=0.2 & 15,16 \\ \text { Coef. of variation of traits } & \sigma_{x} / \bar{x}=0.2 & 14\end{array}$

(1) Hartvig et al. (2011).

(2) Leads to a functional response where the individual neither starves nor is satiated. Corresponds to a resource concentration equal to the half-saturation coefficient.

(3) Gives a factor for the mortality $\alpha_{\mathrm{p}} \hat{\tau} \approx 1.6 \mathrm{yr}^{-1} \mathrm{~g}^{\mathrm{n}-1}$, which 
corresponds to the level of mortality used in Andersen and Beyer

(2015).

(4) Set to correspond to the growth coefficient in Andersen and Beyer (2015): $A\left(\frac{\hat{\tau} R}{\hat{\imath} R+1}-f_{C}\right) \approx 5 \mathrm{~g}^{1-\mathrm{n}} / \mathrm{yr}$ at $10^{\circ} \mathrm{C}$.

(5) West et al. (2001).

(6) Found by fitting observations of annual reproductive output (Andersen and Beyer 2015)

(7) Beverton (1992). 

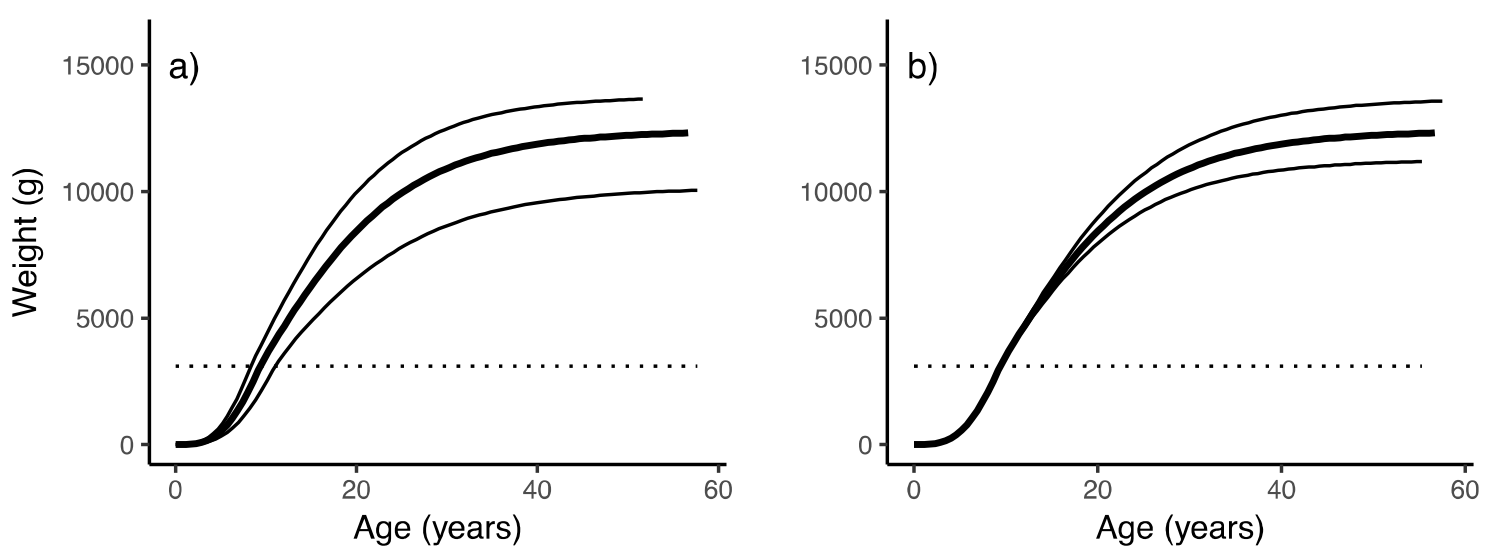

904

Figure 1. Size at age of a long-lived species with asymptotic weight of $14,000 \mathrm{~g}$ (thick

906 lines). (a) Size at age with various boldness $\tau$ shown with thin lines for bolder individuals

(above) and timid individuals (below). (b) Size at age with various investment in

908 reproduction $k_{r}$; higher investment (below) and less investment (above). The growth

curves are drawn until 5 times the age at maturation. 
912
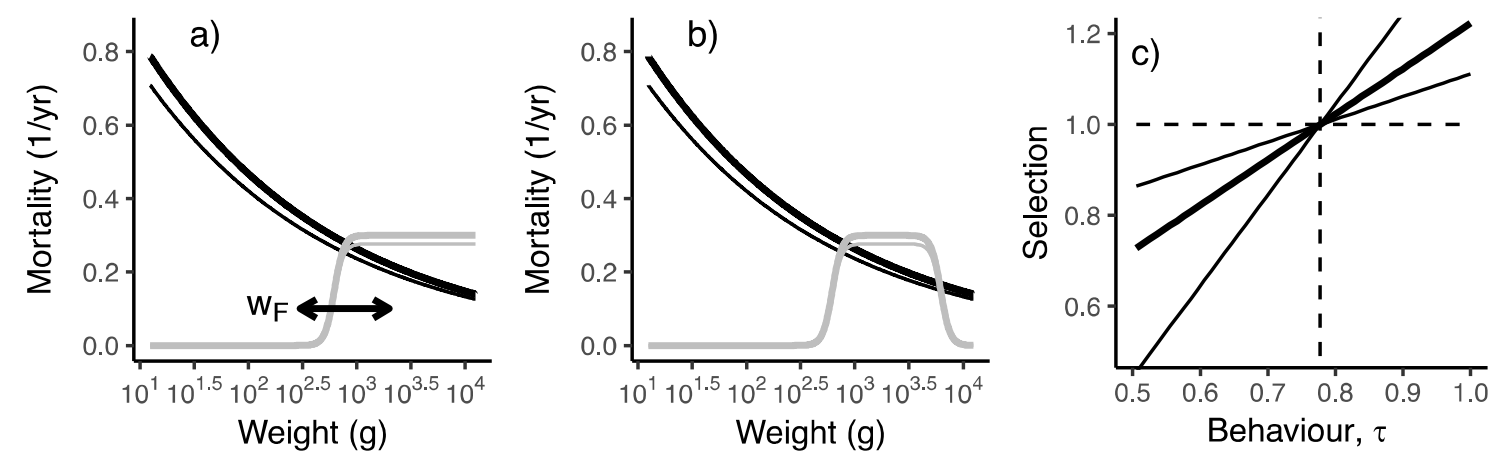

914

Figure 2. Mortality and fisheries selectivity. $(a+b)$ Predation mortality (black) and fishing

916 mortality (grey) for a species with asymptotic size $14,000 \mathrm{~g}$ with boldness $\tau=0.9$

(thick) and $\tau=0.8$ (thin) and fishing mortality $F_{0}=0.3 \mathrm{yr}^{-1}$. (a) Fisheries trawl selectivity

918 defined by the inflection point at $w_{F}$; (b) harvest slot (aka gill-net) selectivity where the width is fixed and the entire slot is moved with $w_{F}$; (c) Boldness-selective harvest for

920 three values of the selection strength $b_{F}: 0$ (horizontal dashed) and 0.5, 1 (thick line) and 2. 


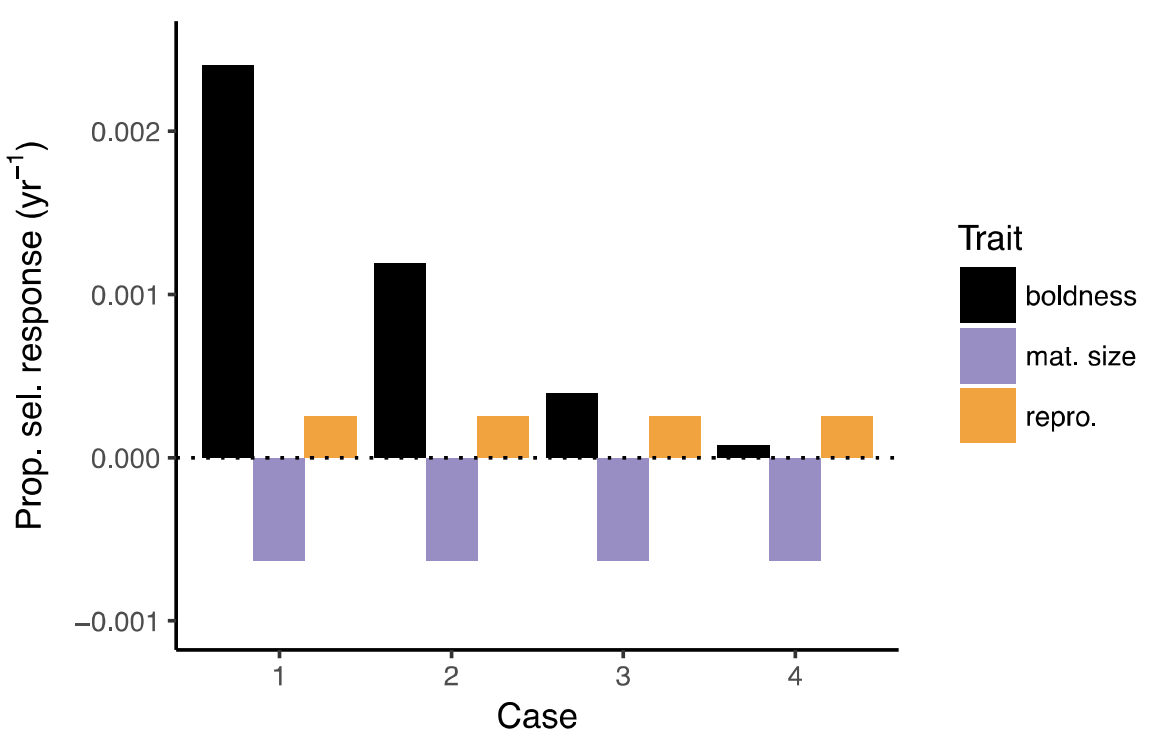

Figure 3. Proportional selection response for four selectivity scenarios: 1: random

926 harvest; 2 : size-selective harvest with a trawl-like selectivity; 3: boldness-selective harvest, and 4: both size- and boldness-selective harvest. The colour codes show

928 proportional selection response for: reproductive investment (orange), boldness $\tau$ (black) and maturation size (magenta). Asymptotic size 14,000 g and fishing mortality $930 \quad F_{0}=0.3 \mathrm{yr}^{-1}$. 

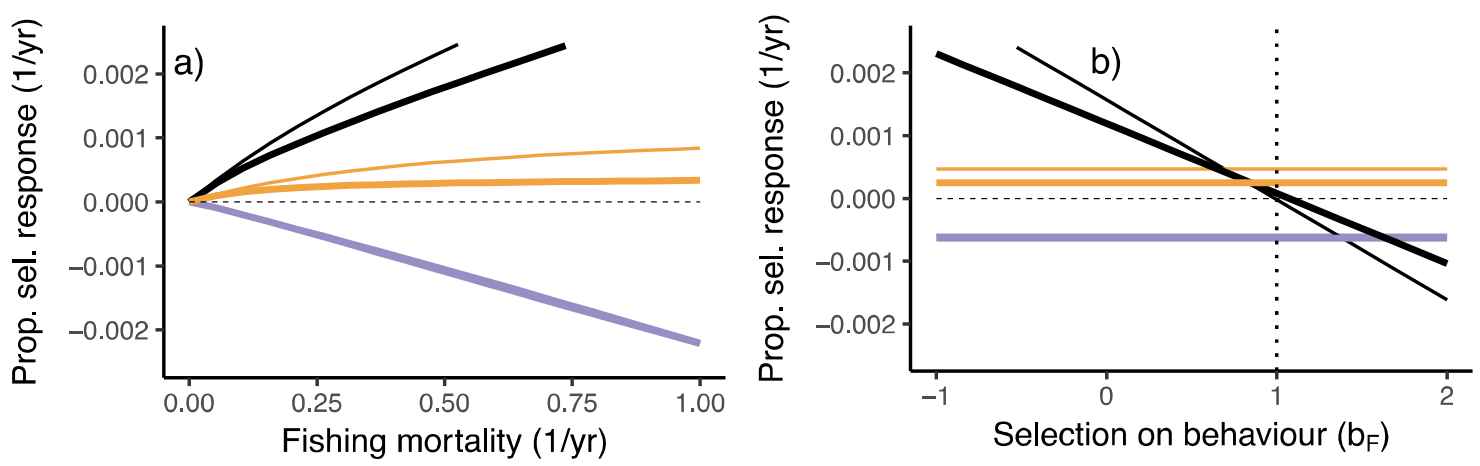

936 Figure 4. Proportional selection responses as a function of fishing mortality without selection on behavior $\left(b_{F}=0\right)(a)$ and as a function of the strength of selection on

938 boldness for $F_{0}=0.3 \mathrm{yr}^{-1}$ for the case with a trawl-type size selection. Line width represents asymptotic size; thin: $140 \mathrm{~g}$, thick: $14,000 \mathrm{~g}$. The vertical dashed line in panel

940 b corresponds to the selection on behavior used in Figure 3 for case 3 . Reproductive investment (orange), boldness $\tau$ (black) and maturation size (magenta). 

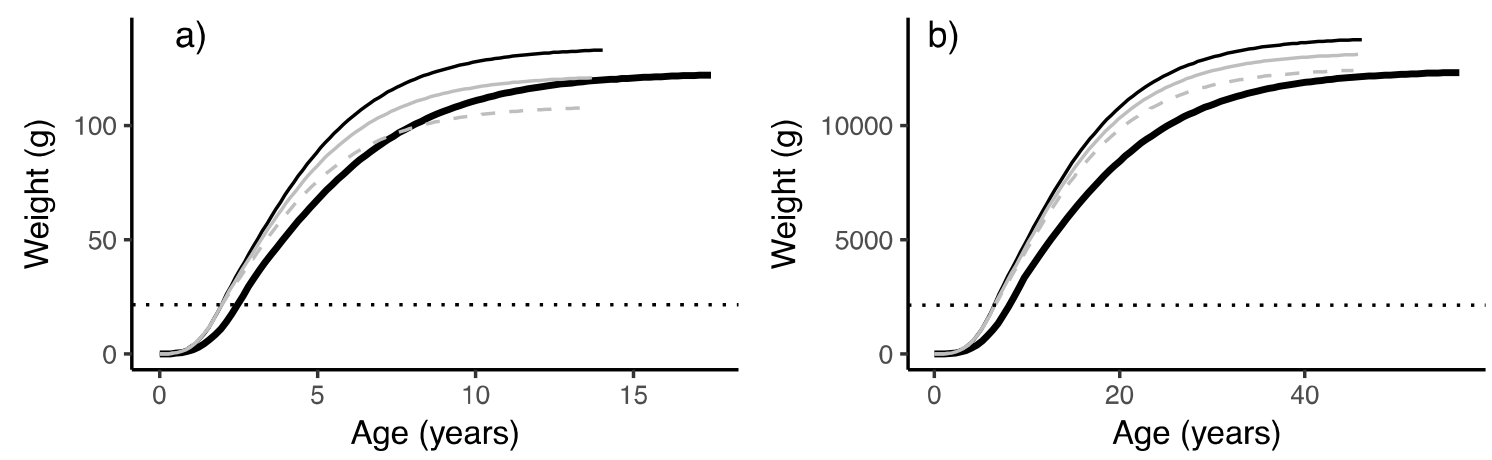

944 Figure 5. Size-at-age curves after 200 years of selection on species with asymptotic size $140 \mathrm{~g}(\mathrm{a})$ and $14,000 \mathrm{~g}$ (b). Curves represent the three cases of selection: without

946 selection (thick), after only size-dependent selection (case 2; thin), after selection on boldness only (irrespective of size) (case3; grey dashed), and combined selection on size

948 and boldness (case 4; grey). The curves are drawn until 5 times the age at maturation to illustrate the effect of selection on age at maturation. $F_{0}=0.3 \mathrm{yr}^{-1} ; b_{F}=1$; the dotted 950 line is at size at maturation. 

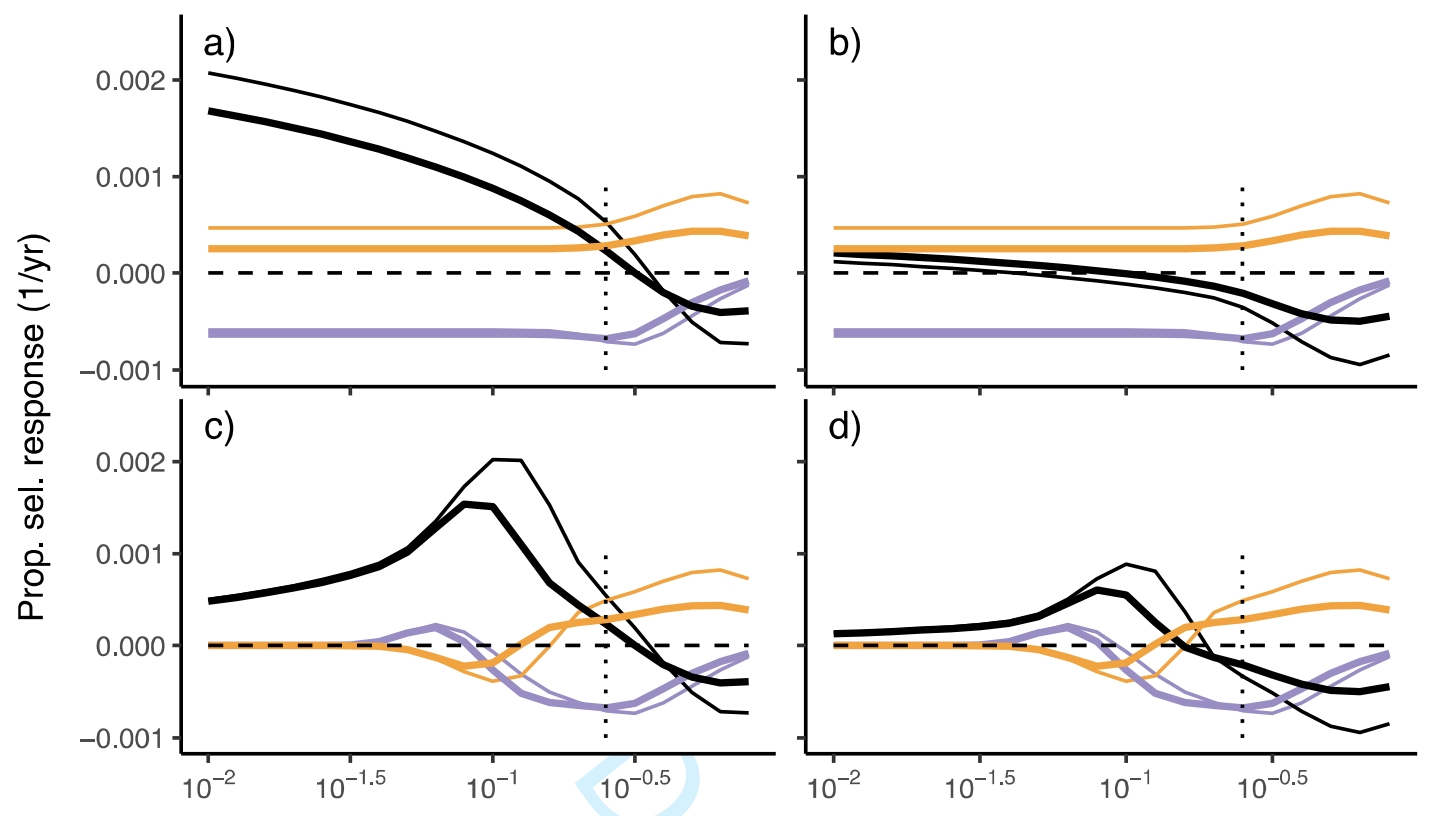

956

Start of fishing relative to asymptotic weight, $\eta_{F}$

Figure 6. Proportional selection responses as functions of the mid-point of selectivity

958 relative to asymptotic size $\left(\eta_{F}\right)$ for a trawl selectivity pattern (Figure $2 a$ ) (a and b) and for a slotted size-selectivity (Figure 2b) (c and d). Panels and c: without selection on

960 boldness $b_{F}=0$; panels $\mathrm{b}$ and $\mathrm{d}$ : with selection on boldness $b_{F}=1$. Reproductive investment (orange), boldness $\tau$ (black) and maturation size (magenta). Vertical dotted

962 line shows size at maturation. The case with entirely unselective mortality as baseline case corresponds to the left edge of panel a, while selection only on boldness

964 corresponds to the left edge of panel b. Line width represents asymptotic size; thin: 140 g, thick: $14,000 \mathrm{~g}$. 

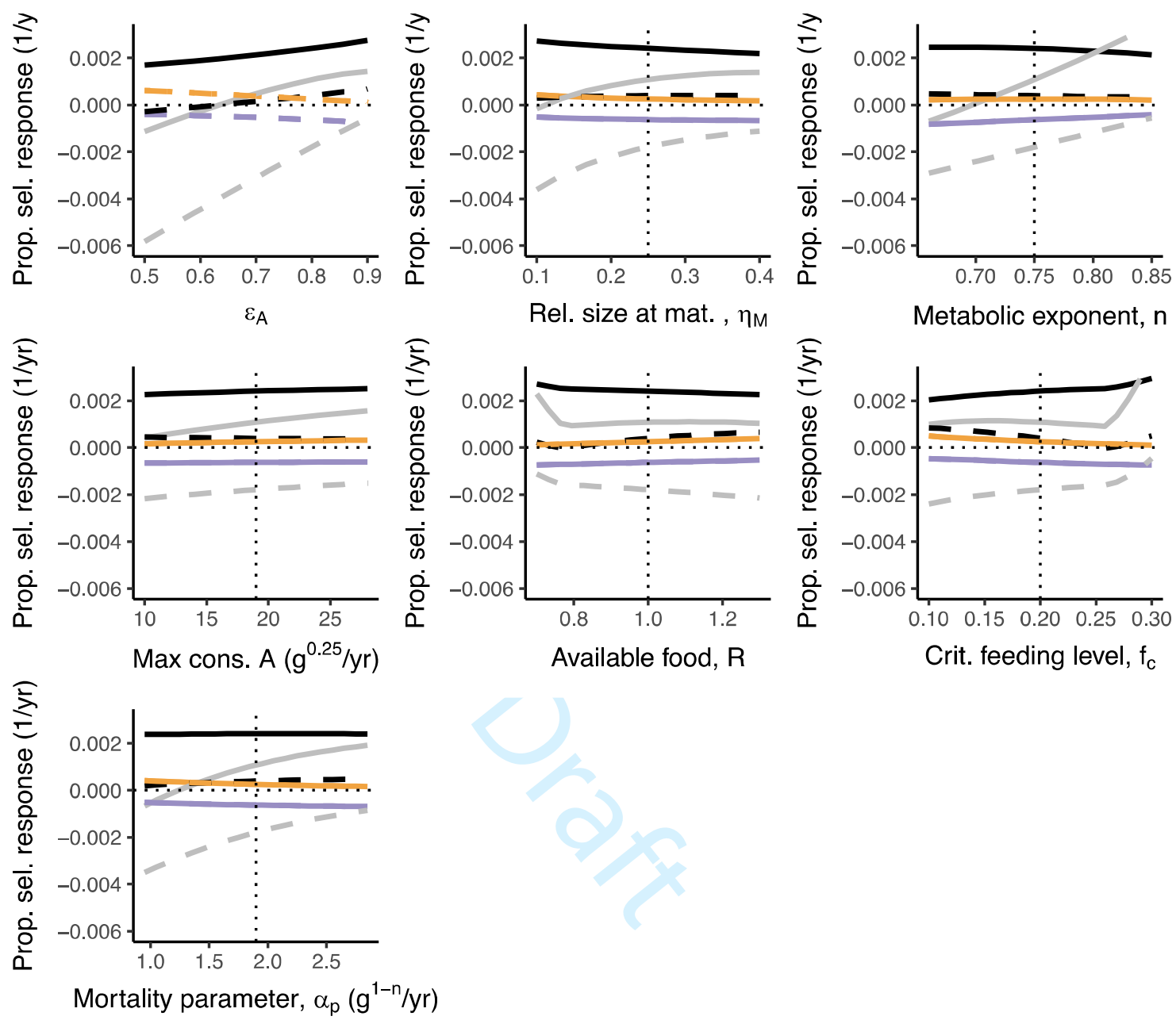

968

970 Figure 7. Sensitivity of selection responses to changes in the fundamental parameters. Reproductive investment (orange), boldness $\tau$ (black) and maturation size (magenta),

972 asymptotic size (grey). Solid lines are without selection on boldness $b_{F}=0$; dashed lines with selection on boldness $b_{F}=1$. 